\title{
MAPAS DA DESORDEM
}

Nayara Marfim é mestre e doutoranda em Literatura, Cultura e Contemporaneidade pela PUC-Rio. E-mail: nmarfim@gmail.com

\section{Resumo}

Este trabalho oferece um exercício crítico de leitura que aproxima as obras animalescos (2013), de Gonçalo M. Tavares, e eles eram muitos cavalos (2001), de Luiz Ruffato, do que considero chamar de uma cartografia do presente. Partindo de um olhar que enxerga nas obras mencionadas mapas da desordem, procuro discutir como ambas as obras debatem e desafiam lugares-comuns, construindo um modo político-poético de intervir na realidade contemporânea.

\begin{abstract}
This paper provide a critical exercise of reading which approximates the works animalescos (2013), of Gonçalo M. Tavares, and eles eram muitos cavalos (2001), of Luiz Ruffato, than I consider say is a cartography for this time. Assuming a look that sees these works mentioned as a disorder maps, I try to think how both works discuss and challenge commonplaces, building a political and poetic way to intervene in contemporary reality.
\end{abstract}

O mapa é aberto, é conectável em todas as suas dimensões, desmontável, reversível, suscetivel de receber modificações constantemente. Ele

pode ser rasgado, revertido, adaptar-se a montagens de qualquer natureza, ser preparado por um indivíduo, um grupo, uma formação social. Pode-se desenhá-lo numa parede, concebê-lo como obra de arte, construí-lo como uma ação política ou como uma meditação. [...] Um mapa é uma questão de performance.

Deleuze e Guatarri, Mil Platôs

\section{1) Notas introdutórias}

Escrever um texto é sempre difícil. Que caminho tomar?

Apresento minha escolha: oferecer um exercício crítico de leitura que aproxime as obras animalescos (2013), de Gonçalo M.Tavares, e eles eram muitos cavalos (2001), de Luiz Ruffato, do que considero chamar de uma cartografia do presente. Partindo de um olhar que enxerga nas obras mencionadas mapas da desordem, busco discutir como ambas debatem e desafiam lugares-comuns, construindo um modo político-poético de intervir na realidade contemporânea.

Três pontos:

(i) A ideia inicial surgiu de uma entrevista ${ }^{1}$ que li sobre animalescos, na qual o jornalista dizia que a obra de Gonçalo Tavares já havia sido definida como uma cartografia da desordem humana. A identificação foi imediata. Imediata também a aproximação de eles eram muitos cavalos dessa noção.

1 Disponível em http://g1.globo.com/platb/maquinadeescrever/2014/02/09/goncalo-m-tavares-o-meutrabalho-e-iluminar-palavras/. Acesso em: 25/11/2015 
(ii) A guinada pós-estruturalista das últimas décadas trouxe para a geografia um novo entendimento sobre a natureza dos mapas e seus princípios de representação. Superando seu emprego como a ciência da representação gráfica de uma realidade estática no papel, os cartógrafos da atualidade enfrentam agora o desafio de estudar a natureza performativa e dinâmica dos mapas. Nessa perspectiva, a cartografia começa a ser entendida como uma atividade que procura apresentar situações, espaços e práticas humanas que se encontram em um processo contínuo de criação.

(iii) Com Gilles Deleuze e Félix Guattari (1995) a cartografia, mais do que adquirir o estatuto de método, torna-se um modo de pensamento que cria seus próprios movimentos e desvios. Assim, no lugar de representar objetos, constrói, por meio de fragmentos, um mapa do presente em constante movimento de produção. Aqui, o sentido da cartografia é de quebra de dualismos, de acompanhamento de processos, conexões de rede ou rizomas: "A cartografia surge como um princípio do rizoma que atesta, no pensamento, sua força performática, sua pragmática um princípio inteiramente voltado para uma experiência ancorada no real" (DELEUZE, 1995, p.21).

\section{2) Mirei no mapa e caí na experiência ancorada no real. Do que estou falando?}

Uma reflexão sobre textos que, cada um à sua maneira, buscam intervir na realidade contemporânea, me convoca a discutir o crescente interesse pela questão dos novos realismos no universo artístico da atualidade, tendo como ponto de partida a formulação de Hal Foster sobre o que convencionou-se chamar, a partir de nomenclatura introduzida pelo autor, de "retorno do real".

Em livro homônimo (2014), Foster, por meio da releitura da história das vanguardas no campo das artes plásticas, busca ultrapassar o que aponta como os dois modelos representativos predominantes na crítica das últimas décadas: o modelo referencial e o simulacral. O modelo referencial, segundo Karl Erik Schøllhammer (2012), entende as imagens e os signos como ligados aos referentes, aos temas iconográficos ou às coisas reais do mundo da experiência. No modelo simulacral, por sua vez, "todas as imagens são consideradas representações de outras imagens, o que converte todo o sistema representativo, inclusive o realismo, em um sistema autorreferencial" (SCHØLLHAMMER, 2012, p.135).

Inspirado pelo pensamento de Lacan (1953), Foster abre então um terceiro caminho entre o "realismo referencial" e o "realismo simulacral", propondo a ideia de um "retorno do real" como alternativa ao pensamento crítico da época. Partindo do conceito lacaniano do traumático como um encontro falho com o Real, Foster propõe o termo "realismo traumático" para denominar imagens que, na derrota representativa, refletem a compulsão de repetição desse encontro fracassado com o Real. Aqui, o autor segue a distinção de Freud entre repetição e reprodução e sugere que essas imagens, na impossibilidade de 
reproduzir o trauma irrepresentável, colocam em cena o Real pela repetição, indicando-o na ruptura da imagem através da qual atinge o espectador afetivamente.

Esse "realismo traumático" foi caracterizado por meio de exemplos da arte das últimas décadas do século XX (como a exposição "Morte na América”, de Andy Warhol) que, no lugar de reproduzir a realidade reconhecível, procuram repetir eventos traumáticos “com a menor intervenção e mediação simbólica possível, provocando efeitos estéticos de repulsa, desgosto e horror" (SCHØLLHAMMER, 2005, p.214).

Schøllhammer (2009), no entanto, extrapola as considerações de Foster para pensar também em outras artes, como a literatura e o cinema, buscando se distanciar criticamente da ideia de "realismo traumático" para identificar, após a emergência de uma estética do choque, o que chamou de "realismo afetivo e performático". Com isso o autor propõe certo afastamento da ideia tanto de uma cultura do trauma quanto de "um realismo tradicional e ingênuo em busca da ilusão de realidade" e abre caminhos para um enfoque no qual a arte possa ser compreendida na sua capacidade de intervir na realidade e de agenciar experiências perceptivas, afetivas e performáticas que se tornam reais.

\section{3) Duas cartografias do caos}

Um escritor brasileiro publica, no ano de 2001, um romance de estrutura não linear composto por 70 fragmentos, cujo único elo é o fato de todas as narrativas ocorrerem no dia 9 de maio de 2000, na cidade de São Paulo. Um escritor português publica no ano de 2013 um livro que reúne 39 micronarrativas que surgem como alucinações, sem parágrafos e paragens, cujo elo principal é a insistente tematização da vulnerável condição humana.

Dois livros aparentemente distantes no espaço e tempo da crítica contemporânea, mas que aqui se aproximam por apresentarem, cada um à sua maneira, encenações gráficas do presente, tornando-se obras exemplares daquilo que chamamos de um novo realismo, aqui definido pela vontade de alguns escritores relacionarem sua produção com a realidade sociocultural da qual fazem parte, trazendo esse contexto esteticamente para dentro das obras.

\section{1) O espaço da cidade}

Em eles eram muitos cavalos lemos uma tentativa de encenar São Paulo, conhecida metrópole de engarrafamentos, conglomerados econômicos e parques artificiais. No livro, não tendo acesso a um narrador que descreva a cidade ou estabeleça uma linha narrativa entre os fragmentos, mergulhamos no caótico território pela colagem de restos da urbe e do relato de histórias acontecidas em um dia na vida de diferentes anônimos que lá habitam. Como uma instalação literária - definição apresentada em diferentes momentos pelo autor para definir sua obra - somos expostos a um emaranhado de fios que compõe o mapa da cidade. 
Primeiro livro publicado por Luiz Ruffato sob a categoria romance, a obra rendeu ao autor a consagração artística por meio de dois prêmios ${ }^{2}$ e grande reconhecimento da crítica, definindo Ruffato como um dos principais nomes da literatura brasileira do século XXI, e se apresentando como a primeira criação artística de um projeto literário que viria a ser conhecido posteriormente pelo público. Com a publicação de Inferno Provisório, coleção composta por 5 livros que também trazem a cidade de São Paulo como cenário, somos apresentados ao declarado interesse do autor de intervir politicamente na realidade por meio da tematização de personagens comumente apagados nas narrativas literárias: a classe operária.

Apesar da declarada escolha temática, o engajamento de seu projeto não se define tanto pelo conteúdo quanto pela escolha formal de procedimentos estéticos que assumem a fragmentação como estilo e a precariedade como sintoma ${ }^{3}$ de época. É o que observamos na ardilosa utilização de artifícios formais já considerados comuns em parte da produção contemporânea, como a incorporação de uma linguagem previamente considerada nãoliterária (horóscopos, listas e santinhos, por exemplo), o uso de formas breves, a utilização de bricolagens, a escassez de pontuação e a mistura de vozes narrativas. Com Ruffato, entretanto, temos a explícita potencialização desses recursos como forma não apenas de criar efeitos de realidade, mas também de, a partir de uma compreensão da escrita como potente campo de experiência política, resistência estética e abertura de múltiplas possibilidades, romper a reprodução formal de um discurso de orientação hegemônicoburguesa. Em suas palavras:

(...) o romance tradicional, tal como o conhecemos, nasce no século 18 como instrumento de descrição da realidade do ponto de vista de uma classe social ascendente, a burguesia. Ou seja, o romance ideologicamente serve a uma visão de mundo específica. Como usar a forma sem trair o conteúdo? Ou, de outra maneira: qual a forma adequada de representar o ponto de vista da classe média baixa, ou do trabalhador urbano? (RUFFATO, 2008, p. 321).

Dessa forma, ao entender a linguagem literária como prática social que reflete e age sobre o mundo, identificamos o fragmentário como estilo que melhor apresenta a dissolução da nossa realidade. Desmantelamento narrativo aqui entendido como a relação ética do autor com a escrita, encenada por um modo de ser da cidade que se impõe ao texto. Assim, texto e vida, embora precários e fragmentados, são construídos pela justaposição das diferenças e contágio de um pelo o outro. Com isso, a precariedade da vida na cidade e da realidade urbana se apresentam pela ruptura abrupta com a linearidade de um estilo literário que se supunha totalizante:

\footnotetext{
${ }^{2}$ APCA (Associação Paulista de Críticos de Arte) e Machado de Assis, da Fundação Biblioteca Nacional.

${ }^{3}$ Esta ideia está apresentada no texto disponível em:http://www.conexoesitaucultural.org.br/wpcontent/uploads/2010/05/da-impossibilidade-de-narrar.pdf. Acesso em 01/12/2015 
Por exemplo, a insistência da construção de capítulos estanques, que significariam a precariedade, a falta de permeabilidade das relações sociais. A precariedade das falas das pessoas, que não conseguem se comunicar, porque a comunicação é efêmera em São Paulo. A precariedade da arquitetura da cidade, a precariedade da arquitetura do romance, a precariedade do próprio espaço urbano ${ }^{4}$.

A adoção de um estilo próprio como possibilidade de rompimento com a forma clássica do romance é ponto de aproximação que encontro entre Ruffato e Gonçalo M. Tavares. Afinal, se até aqui temos a proposta de uma instalação literária como possível resposta ao impasse brasileiro, que categoria dar ao livro português que reúne 39 micronarrativas?

\section{2) O tempo do homem}

Publicado em junho de 2013, animalescos é o terceiro livro da trilogia "Canções" e a $32^{\circ}$ produção de Gonçalo $\mathrm{M}$. Tavares. $\mathrm{O}$ autor, que como Ruffato também apresenta a proposta de um projeto literário, é um escritor voraz, conhecido por produzir livros que variam drasticamente em forma e conteúdo: "Não sei qual é esse desenho, nem o que ele está a representar, mas cada livro é um traço de um desenho, que é a obra que se vai construindo aos poucos"

Já tendo sido definido como anti-romance, anti-ensaio e anti-conto, animalescos é um traço de seu desenho que aborda tematicamente a loucura da condição humana em um discurso desterritorializado que, mais do que apresentar ideias claras e distintas, busca verticalizar experiências e sensações que são ao mesmo tempo opacas e universais: estamos todos em queda, lutamos pela sobrevivência. E é no tempo presente e urgente da sobrevivência que as histórias se constroem.

Em um ritmo acelerado, sem parágrafos e pontuações, com pausas marcadas usualmente apenas por vírgulas, o texto parece querer se mostrar como uma prosa passível de ter como cenário um hospital psiquiátrico. Trazendo fortes críticas à realidade contemporânea, fala-se das máquinas, da relação dos humanos com os poderes instituídos, da forma como todos caminham em linha reta com o único objetivo de poder continuar caminhando. Mas tudo isso em um discurso fragmentado e desconexo que traz para o leitor a possibilidade de romper o traçado e escolher seu percurso.

Dentre as entradas possíveis para o labirinto que Tavares oferece estão histórias como a de uma mulher que pede esmolas para se alimentar das moedas recebidas, um encontro com uma multidão de loucos sem cabeça, humanos que devoram os ferros de um

4 Disponível em: http://www.heloisabuarquedehollanda.com.br/entrevista-a-luiz-rufato/. Acesso em $10 / 12 / 2015$

5 Disponível em http://g1.globo.com/platb/maquinadeescrever/2014/02/09/goncalo-m-tavares-o-meutrabalho-e-iluminar-palavras/. Acesso em: 02/12/2015 
helicóptero caído do céu, homens que arrancam a cabeça porque é lá que mora o medo e até um maluco autodidata que ficou maluco sem a ajuda de ninguém. Mas, não havendo uma hierarquia temporal necessária entre as pequenas ficções, é permitido ao leitor estabelecer as redes e conexões que melhor identificar para compor, por meio das enxutas micronarrativas, seu mapa da realidade humana.

Exatidão ambígua que o autor sustenta ao longo do tempo de leitura através de um relato labiríntico e desterritorializado, constituído por uma escassez de palavras que simultaneamente condensam e multiplicam significados em um ritmo vertiginoso. Não sendo exigida uma interpretação hermenêutica do leitor, são jogados, por todas as frestas da narrativa, problemas e impasses universais. Fugindo ao tradicionalismo de um discurso panfletário, o livro torna-se, assim, uma potente estratégia de intervenção política. Assim propõe o autor:

(...) a literatura deve interferir na política através do aumento da lucidez individual das pessoas. Pessoalmente, não me interessa uma política partidária, mas uma política no sentido de intervenção na cidade, na pólis, na forma como os homens vivem, e penso que aí a literatura é essencial, por ser o espaço da reflexão, de uma certa distância em relação aos acontecimentos e às circunstâncias do mundo ${ }^{6}$.

Nesse sentido, para colocar essas questões em cena, animalescos nos impõe a presença de um discurso tortuoso e veloz, que atira para todos os lados, criando um ambiente em que as palavras parecem ser jogadas no texto com a menor mediação simbólica possível, extrapolando sua significação primeira para apresentar outras coisas. Narrativa caótica de um texto criado com as estratégias oportunas (enxugar palavras, reunir diferentes significados em um único significante, criar uma narrativa que não para, que não narra) para agenciar, no leitor, experiências afetivas que se tornam reais:

Não gosto da literatura com aquela emoção presente nos programas de televisão que entrevistam pessoas que contam seus casos trágicos de doenças etc. Vendo esses programas ficamos emocionados e se for necessário até choramos, nos sentimos comovidos, mas passados cinco minutos o mesmo programa mostra um cantor alegre, e já nos esquecemos daquele caso trágico. Esse tipo de emoção que atinge um pico muito alto rapidamente é perigosa, engana, não é empática nem humana. Não gostava que as pessoas chorassem ao lerem meus livros, mas que pudessem guardar um ano ou dois anos depois uma imagem, que ainda os comove ou perturba. Uma emoção que dure anos, e não apenas 1 minuto, de intensidade baixa mas de longa duração, é uma definição possível da emoção que me agrada ${ }^{7}$.

6 Disponível em http://g1.globo.com/platb/maquinadeescrever/2014/02/09/goncalo-m-tavares-o-meutrabalho-e-iluminar-palavras/. Acesso em: 02/12/2015

7 Disponível em http://g1.globo.com/platb/maquinadeescrever/2014/02/09/goncalo-m-tavares-o-meutrabalho-e-iluminar-palavras/. Acesso em: 02/12/2015 


\section{4) Cartografar a desordem é sempre criar uma ordem possível?}

Conforme citado no início deste texto, a ideia inicial que deu origem ao presente trabalho surgiu de uma entrevista sobre animalescos, na qual o jornalista dizia que a obra de Gonçalo M. Tavares já havia sido definida como uma cartografia da desordem humana. Em outra matéria de jornal, no entanto, um jornalista arriscou: "cartografar a desordem é sempre criar uma ordem possível"8.

Seria possível compreender as obras aqui trabalhadas nessa perspectiva?

Nossa aposta é que não. E dela surgiu a linha argumentativa exposta. Partimos, ao contrário, da ideia de que, diante da impossibilidade de apreensão e simbolização da realidade como ela é, nossos autores trabalham inventivamente, buscando recursos estéticos e formais que subvertem o próprio fazer literário (e não seria próprio da literatura subverter-se para continuar existindo, resistindo?) para encenar situações que desnaturalizam as formas e hierarquias de poder instauradas. São obras, portanto, aqui entendidas como narrativas que no lugar de oferecer caminhos, apontam para o caos, chamam a desordem pelo nome, invocam a catástrofe, e - felizmente - não oferecem consolo.

\section{Referências}

DELEUZE, Gilles; GUATTARI, Félix. Mil platôs. Capitalismo e esquizofrenia. Volume 1. São Paulo: Editora 34, 1995.

FOSTER, Hal. O retorno do real. São Paulo: Cosac Naify, 2014

LACAN, Jacques. O Simbólico, o Imaginário e o Real (1953). Em Nomes-do-Pai. Rio de Janeiro: Jorge Zahar, 2005.

RUFFATO, Luiz. Até aqui, tudo bem! (Como e por que sou romancista - versão século 21). In: MORGATO, Izabel \& GOMES, Renato Cordeiro. Espécies de espaço:territorialidades, literatura, mídia. Belo Horizonte: Editora UFMG, 2008.

eles eram muitos cavalos(2001). São Paulo: Companhia das Letras, 2013.

SCHOLLHAMMER, Karl Erik. Ficção brasileira contemporânea. Rio de Janeiro: Civilização Brasileira, 2009.

--_-- O espetáculo e a demanda do real. In: FILHO, João F. e HERSCHERMANN, Micael. Comunicação, Cultura e Consumo: a [des]construção do espetáculo contemporâneo. Rio de Janeiro: e-papers, 2005, p.207-225.

\footnotetext{
8 Disponível em http://www.cartacapital.com.br/blogs/outras-palavras/goncalo-tavares-a-literatura-parapercorrer-o-verso-3835.html. Acesso em 09/12/2015 
- (2012). Realismo afetivo: evocar realismo além da representação. Estudos de Literatura Brasileira Contemporânea, (39), 129-150. https://dx.doi.org/10.1590/S231640182012000100008

TAVARES, Gonçalo M. animalescos. Lisboa: Relógio D’Água Editores, 2013. 